\title{
The French national survey on food consumption of children under 3 years of age - Nutri-Bébé 2013: design, methodology, population sampling and feeding practices
}

\author{
Jean-Pierre Chouraqui ${ }^{1, *}$, Gabriel Tavoularis ${ }^{2}$, Yves Emery $^{3}$, Aurée Francou ${ }^{2}$, \\ Pascale Hébel $^{2}$, Magali Bocquet ${ }^{4}$, Régis Hankard ${ }^{5,6}$ and Dominique Turck ${ }^{7}$ \\ 'Paediatric Nutrition and Gastroenterology, Medical and Surgical Department of Paediatrics, Centre Hospitalier \\ Universitaire Vaudois, 21 rue du Bugnon, 1011 Lausanne, Switzerland: ${ }^{2}$ CREDOC (Centre de Recherche pour \\ I'Etude et l'Observation des Conditions de Vie), Paris, France: ${ }^{3}$ TNS Sofres, Montrouge, France: ${ }^{4}$ SFAE (Secteur \\ Français des Aliments de I'Enfance), Paris, France: ${ }^{5}$ INSERM UMR 1069 'nutrition, croissance, cancer', Université F. \\ Rabelais, Tours, France: ${ }^{6}$ Unité Mobile Nutrition, CHU Tours, Tours France: ${ }^{7}$ Université de Lille et INSERM U995, \\ Lille, France
}

Submitted 18 November 2016: Final revision received 24 July 2017: Accepted 7 August 2017: First published online 2 November 2017

\begin{abstract}
Objective: To update the data on food consumption and practices in children under 3 years of age in metropolitan France.

Design: The Nutri-Bébé 2013 cross-sectional study selected a random sample, according to the quota sampling method. After giving their informed consent, parents had to record the food consumption during three non-consecutive days framed by two face-to-face interviews, using for quantitative information different portion size measurement aids.

Results: One thousand one hundred and eighty-four children were enrolled. Mothers' mean age was 30.8 (sD 5.4) years; 38\% were primiparous; $89 \%$ lived with a partner; $60 \%$ had an occupation. Of the infants younger than 4 months, $31 \%$ were breast-fed. One thousand and thirty-five children consumed infant formula followed by growing-up milk in $63 \%$ of them; solid foods were introduced at a mean age of 5.4 (SD 2.13) months. From 8 months onwards, $25 \%$ of children consumed the same foods as their parents on a more or less regular basis; $29 \%$ ate in front of a screen, with a daily average screen time of 43.0 (SD 40.4) min.

Conclusions: This robust survey highlights the low prevalence and duration of breast-feeding in France and shows a modest improvement since the previous survey of 2005 in the observance of recommendations concerning other feeding practices. The frequent consumption of adult foods and the screen time are of concern.
\end{abstract}

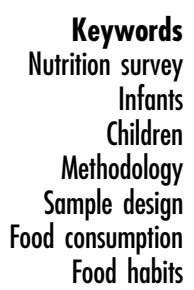

The main objective of dietary surveys is to assess nutritional intakes of a given population. Their analysis allows identifying public health issues regarding food and nutrition, and if necessary, to establish actions aimed at improving food and nutrition education in this population. Diet is essential for growth and development during the first years of life and also in the medium and long term determines risk of non-communicable diseases ${ }^{(1-3)}$.

The Secteur Français des Aliments de l'Enfance (SFAE) has conducted and funded a national survey on eating behaviours and food consumption of infants and young children every 8 years for more than three decades $\left(1981,1989,1997\right.$ and 2005) ${ }^{(4-7)}$. Over the years, the study population has been modified to include children from birth to 35 months of age, and the methodology has gradually become refined. The specific features of the latest survey in 2013 were the inclusion of breast-fed (BF) infants as well as children receiving 'growing-up milk' (GUM); an increased sample size in each age group to improve the statistical power of the survey; and a direct measurement of the children's weight.

The objectives of the Nutri-Bébé SFAE 2013 study were to:

1. study the eating behaviours and food, macro- and micronutrient consumption of infants and young children living in France; and

2. compare the observed feeding practices with existing European and French recommendations. 
The purpose of the present paper is to describe the methodology, the population and the sampling procedure of the 2013 survey, as well as the feeding practices of infants and young children in 2013 compared with 2005.

\section{Methods}

Nutri-Bébé 2013 is the fifth edition of a survey conducted every 8 years since 1981 by the SFAE. Overall, the methodology and the procedures followed are in line with the guideline set by the European Food Safety Authority (EFSA) Expert Group on Food Consumption Data and the Institut Français de Nutrition $\left(\right.$ IFN) ${ }^{(8,9)}$.

\section{Sample design}

The Nutri-Bébé 2013 survey is an observational crosssectional study conducted in children living in France aged $15 \mathrm{~d}$ to 35 months. It includes a section on eating behaviours and a section on food consumption. The present survey is based on a randomly selected sample with sociodemographic characteristics similar to the general population living in mainland France (i.e. excluding Corsica, overseas departments, regions and communities, and New Caledonia). A quota sampling method was used: sampling was stratified by residential area, size of the urban agglomeration, infant gender, mother's professional activity (active or inactive before any maternity leave), occupational and socio-occupational status (in French, 'professions et catégories socio-professionnelles' (PCS); classified into three categories: PCS +, PCS - and inactive, as detailed in Table 1) and adjusted for these different characteristics. This stratification was based on the population characteristics of the 2002 census of the National Institute for Statistics and Economic Research (in French, Institut National de la Statistique et des Études Économiques (INSEE); https://www.insee.fr/fr/ffc/docs_ffc/ IP857.pdf).

Inclusion criteria were as follows: (i) informed parental consent to participate in the study; (ii) absence of intercurrent or chronic disease; and (iii) birth weight above $2.5 \mathrm{~kg}$. To ensure comparability with the 2005 survey, the same age-group definitions were used. Eleven age groups that took account of the previous surveys and the key stages of child development were defined: $15 \mathrm{~d}$ to 3 months, 4, 5, 6, 7, 8-9, 10-11, 12-17, 18-23, 24-29 and 30-35 months. Eighty children were planned to be enrolled in each age group, totalling 880 children for the main sample. For the current survey 164 additional nonbreast-fed (NBF) children were added ('oversampling') for comparison with previous studies. The final number of children enrolled in each group is described in Table 2, which also specifies the recruitment method (main sample or oversample). Only BF children were included in the 'eating behaviours' component of the study. In the absence of information on the volume and composition of
Table 1 Description of the socio-occupational categories according to PCS ('professions et catégories socio-professionnelles') classification and prevalence of each category in the French and the survey populations

\begin{tabular}{lcc}
\hline Category & $\begin{array}{c}\text { Prevalence in the } \\
\text { French population } \\
(2002, \%)\end{array}$ & $\begin{array}{c}\text { Prevalence in } \\
\text { the study sample } \\
(n \text { 1184, \%) }\end{array}$ \\
\hline PCS + & 41 & 41 \\
Farmers & & \\
Artisans & & \\
Shopkeepers and similar & & \\
positions & & \\
Liberal professionals & & \\
Entrepreneurs and & \\
corporate executives & \\
Intermediate corporate & \\
administrative/ & \\
commercial positions & \\
Engineers, foremen, & \\
supervisors & \\
Senior public service & \\
managers & \\
Intermediate teaching/ & \\
health-care/public & \\
service positions and \\
similar professions \\
Intellectual/artistic \\
professions \\
PCS- \\
Farm workers \\
Skilled workers \\
Specialised workers \\
Commercial employees \\
Corporate administrative \\
employees \\
Public service \\
employees \\
Personal services \\
employees \\
Inactive \\
\hline
\end{tabular}

ingested breast milk, only data for NBF children were used for the 'food consumption' component of the study. To analyse the consumption of children receiving GUM in age groups older than 1 year, an additional recruitment of ninety-four children consuming GUM and thirty-two who did not consume it was done (Table 2). A total of 1192 children were recruited and 1184 finally enrolled in the study (Fig. 1).

\section{Conducting the survey}

The study was conducted from 3 January to 21 April 2013, by an official polling institute, the TNS Sofres.

After the selection of families by the quota sampling method and obtaining their consent, a first home visit was conducted. An information letter from TNS Sofres explained the objectives of the study, presented the questionnaire and invited the caregivers to take part in the survey. The following information was collected during a face-to-face interview: date of birth and birth weight, verification of inclusion criteria, eating habits, lifestyle and physical activity, mother's age, parity, past or current breast-feeding, number of people in the household, 
occupation (PCS) and level of education of the reference person in charge of the child, socio-economic status and source of advice regarding the child's diet. The employment status of the reference person was classified as 'working' or 'not working' (student, unemployed, without a profession, retired). The level of education included three levels: (i) no education or primary and/or early secondary school; (ii) up to the baccalauréat; and (iii) upper education including university. The respondent could refuse to answer certain questions or discontinue participation in the study at any time.

To measure food consumption, a diary, a measuring jug (Curver 1 litre; gencod 3253920404008), a photographic tool kit to assess food portions, kitchen measuring tools and scales were provided and their use explained to the caregiver. Parents completed the child's consumption diary over a period of three non-consecutive days (two weekdays and one weekend day). A second visit occurred $7 \mathrm{~d}$ later to verify and complete the diary if necessary, and to conduct a face-to-face interview with the mother about eating habits over the survey period. Both interviews were recorded using $\mathrm{CAPI}^{\circledR}$ software (Computer Assisted Personal Interviews; http://www.soft-concept.com). During this visit, the child was weighed (naked, with a clean diaper or underwear) using a Tefal PREMISS PP1000VO scale with a precision of $100 \mathrm{~g}$. If parents did not allow the investigator to weigh the child, a recent record ( $<15$ d earlier for infants, $<1$ month earlier for children over 12 months of age) could be provided; otherwise the child was not included in the study. The weight was compared with WHO standards ${ }^{(10)}$. Weights that were found to be totally inconsistent with the child's age ( $>3 \mathrm{SD}$ or $<3 \mathrm{sD}$ ), presumably due to a measurement error or report, were considered 'aberrant' and are shown in Fig. 2. They were not taken into account in the calculation of mean weight (Fig. 3) or in that of the weight-based nutritional intakes.

\section{Food diaries for the 'consumption' component}

The child's food consumption diary was completed between the two visits of the TNS Sofres investigator. The person in charge of the child was trained to qualitatively and quantitatively report all liquid and solid foods consumed and all drinks, by specifying the exact name of the product, its potential trademark or whether it was 'homemade'. The type of water consumed was noted as being either 'bottled' or 'tap'. For each food type consumed, it was requested that the quantity served (in grams, millilitres or dose) and remaining after the meal be noted, and their ingredients, as far as possible, be weighed using a kitchen scale, or with the help of a measuring cup or packaging information and/or photographs of reference portion sizes. The type (breakfast, morning snack, lunch, afternoon snack, dinner, nocturnal food intake) and timing of food consumption were collected. If applicable, vitamin, mineral or medicine supplements were noted. 


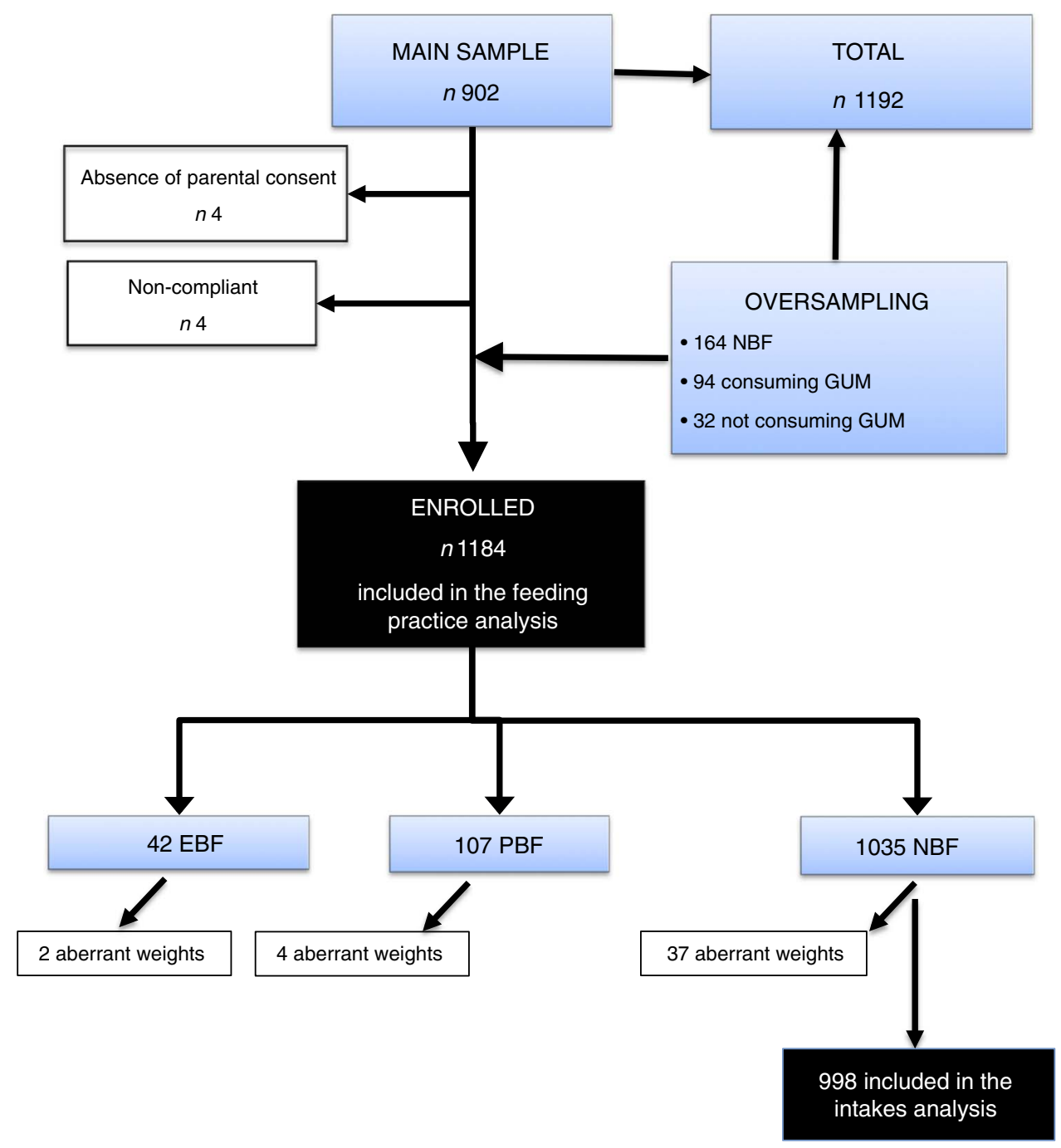

Fig. 1 Flowchart of the study sampling for the French national survey on food consumption of children under 3 years of age (Nutri-Bébé 2013); for details see text and Table 2 (NBF, non-breast-fed; EBF, exclusively breast-fed; PBF, partially breast-fed; GUM, growing-up milk)

During the second visit, the investigator reviewed thoroughly the record with the caregiver and checked the way of reporting the quantities as well as the interpretation of the photographic tool kit to be as close as possible to reality.

\section{Analysis of food diaries}

The Research Centre for the Study and Observation of Living Conditions (in French, Centre de Recherche pour l'Etude et l'Observation des Conditions de Vie (CREDOC)) analysed the food intake diaries. For common foods, "not specific for babies', the 2012 CIQUAL (Centre for Information on Food Quality) composition table elaborated by the French Agency for Food, Environmental and Occupational Health \& Safety (in French, Agence nationale de sécurité sanitaire de l'alimentation, de l'environnement et du travail (ANSES)) was used (after correction of errors), representing 1439 food codes ${ }^{(11)}$. For 'foods specific for babies', nutritional composition was obtained from manufacturers who are members of the SFAE, from product labelling or by calculation based on the average composition of the foods included in the pro$\operatorname{duct}^{(9)}$, representing 1223 food codes. The diaries were analysed by two dietitians who attributed a food code to each food, after verifying all data (consistency check). The actual quantity consumed was calculated for each food. For simple foods containing a single ingredient, the amount consumed $\left(Q_{c}\right)$ corresponded to the amount served $\left(Q_{\mathrm{s}}\right)$ minus the amount remaining $\left(Q_{\mathrm{r}}\right)$ once the meal was over. For complex foods or dishes, the amount of each ingredient was calculated using the following formula: $Q_{\mathrm{c}}=\left(Q_{\mathrm{s}}-Q_{\mathrm{r}}\right) \times p$, where $p$ is the relative weight of the ingredient in the food. A duplicate data entry was performed to prevent any forgetting or mistake in data entry. To use the data, foods were divided into fortysix food categories, including seventeen for 'foods specific for babies' and twenty-nine for common foods (see online supplementary material). 

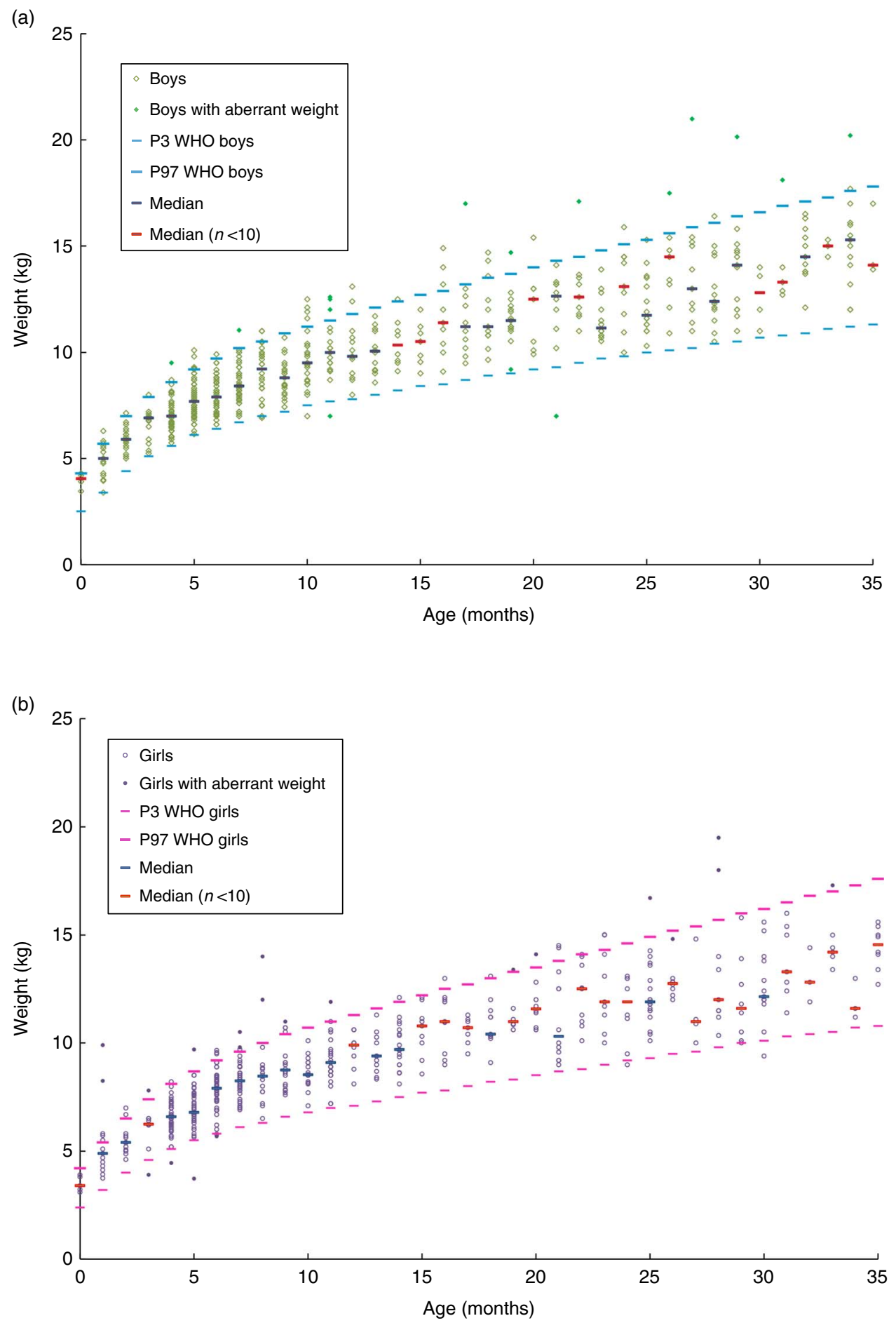

Fig. 2 Distribution of weight by age and gender, relative to the 3rd percentile (P3) and 97th percentile (P97) curves of the WHO Child Growth Standards, among 1035 non-breast-fed children in the French national survey on food consumption of children under 3 years of age (Nutri-Bébé 2013): (a) boys ( $n$ 541); (b) girls ( $n$ 494)

\section{Statistical analysis}

Results were expressed as means and SD. The mean food consumption values were calculated as follows:

$$
A_{a}=\frac{\sum_{k \in a}\left(A_{k 1}+A_{k 2}+A_{k 3}\right) / 3}{N_{\mathrm{a}}},
$$

where $A_{a}$ is the mean daily intake of food $a$ in the age group; $A_{k 1}, A_{k 2}$ and $A_{k 3}$ are the contributions of each individual on the first, second and third days of the survey; and $N_{\mathrm{a}}$ is the size of the age group. The statistical analysis was performed using the statistical software package SAS $^{\circledR}$ version $9 \cdot 2$ (http://support.sas.com/documentation/installcenter/922/). A Pearson's $\chi^{2}$ test was used for comparisons of categorical data 


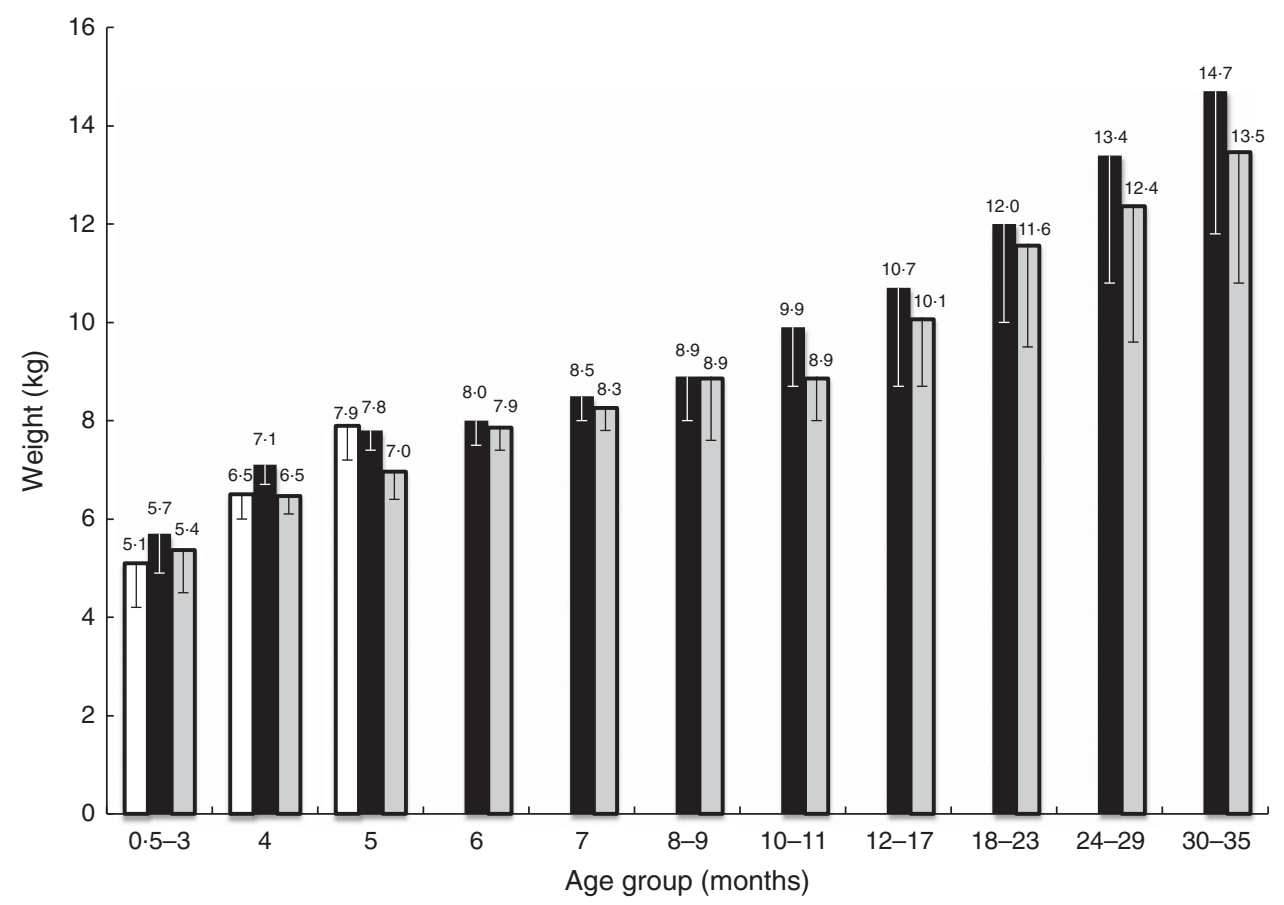

Fig. 3 Mean weight by age of the exclusively breast-fed infants ( $n$ 42; $\square$ ) and of the non-breast-fed children ( $n$ 1035) by age and gender ( $\square$, boys; $\square$, girls; for the number in each age group, see Table 2), with the standard deviation represented by vertical bars, in the French national survey on food consumption of children under 3 years of age (Nutri-Bébé 2013)

either within the 2013 survey or whenever possible with the 2005 survey. Analysis of quantitative data was based on ANOVA and Student's $t$ test. A significance level of 0.05 was used, with $95 \%$ CI.

\section{Results}

\section{Characteristics of the study population}

A total of 1192 children were recruited, 1188 of whom were enrolled due to their parent's consent to participate in the study. Age range was $15 \mathrm{~d}$ to 3 years, and $50 \%$ of children were male. Mean birth weight was 3329 (sD 480) g. Birth weight ranged from 2500 to $3000 \mathrm{~g}$ in $27 \%$ of children, from 3001 to $3500 \mathrm{~g}$ in $41 \%$, from 3501 to $4000 \mathrm{~g}$ in $25 \%$, and was above $4001 \mathrm{~g}$ in $7 \%$.

Among the 1188 enrolled children, four could not be considered in the food consumption analysis due to noncompliance with the study protocol. The NBF children's weights measured during the second visit were distributed as shown in Fig. 2 and their mean value by age as well as that of BF infants is given in Fig. 3. No difference was seen between $\mathrm{BF}$ and NBF infants or between genders. The weights of forty-three children, including six who were BF, were considered aberrant for their age. Among the 1141 children whose weight was considered compatible with their age, 5.4\% were overweight, with a weight-for-age greater than or equal to the 97th percentile of the WHO Child Growth Standards ${ }^{(10)}$, and $7 \%$ were underweight, with a weight-for-age less than or equal to the 3rd percentile of the same charts.

\section{Sociodemographic context}

The mothers of the 1184 children included in the food consumption survey had a mean age of 30.8 (SD 5.4) years, similar to that described in 2005 (30.3 years); $12 \%$ of them were under 25 years old $v .13 \%$ in 2005, $32 v$. 31\% were between 25 and 29 years of age, $33 v .35 \%$ between 30 and 34 years, and 23 v. $21 \%$ were over 35 years (NS). Thirty-eight per cent were primiparous while 39\% were in 2005 (NS); $89 \%$ lived with a partner whereas $92 \%$ did in 2005 $(P=0.006)$. In $2013,96 \%$ of households $v .98 \%$ in 2005 contained at least three people $(P=0.019)$, with a mean of $4 \cdot 1$ (SD 1.3); $60 \%$ of mothers $v .61 \%$ in 2005 had an occupation at the time of the survey (NS). Forty-one per cent were PCS,$+ 53 \%$ were PCS - and 6\% were inactive (Table 1), compared with 39, 53 and $8 \%$, respectively, in 2005 (NS); $46 \%$ of mothers had level 3 postgraduate education; $8 \%$ had no education or primary and/or early secondary school (level 1). Depending on the situation, 39\% of mothers relied on their previous experiences and $60 \%$ on their instincts to feed their child; $31 \%$ asked for advice from their relatives and $58 \%$ sought the advice of a paediatrician, a general practitioner or a health-care professional specialised in early childhood; $22 \%$ took into consideration media advice (Internet, specialised journals) and 2\% considered advice from food manufacturers. Mothers were more likely to seek advice from medical sources if they were primiparous $(P=0.003)$, less than 30 years old $(P=0.047)$ or if the child was under 12 months of age $(P=0 \cdot 0009)$. Multiparous, inactive mothers and those over 35 years of age favoured instinct and previous experience. 


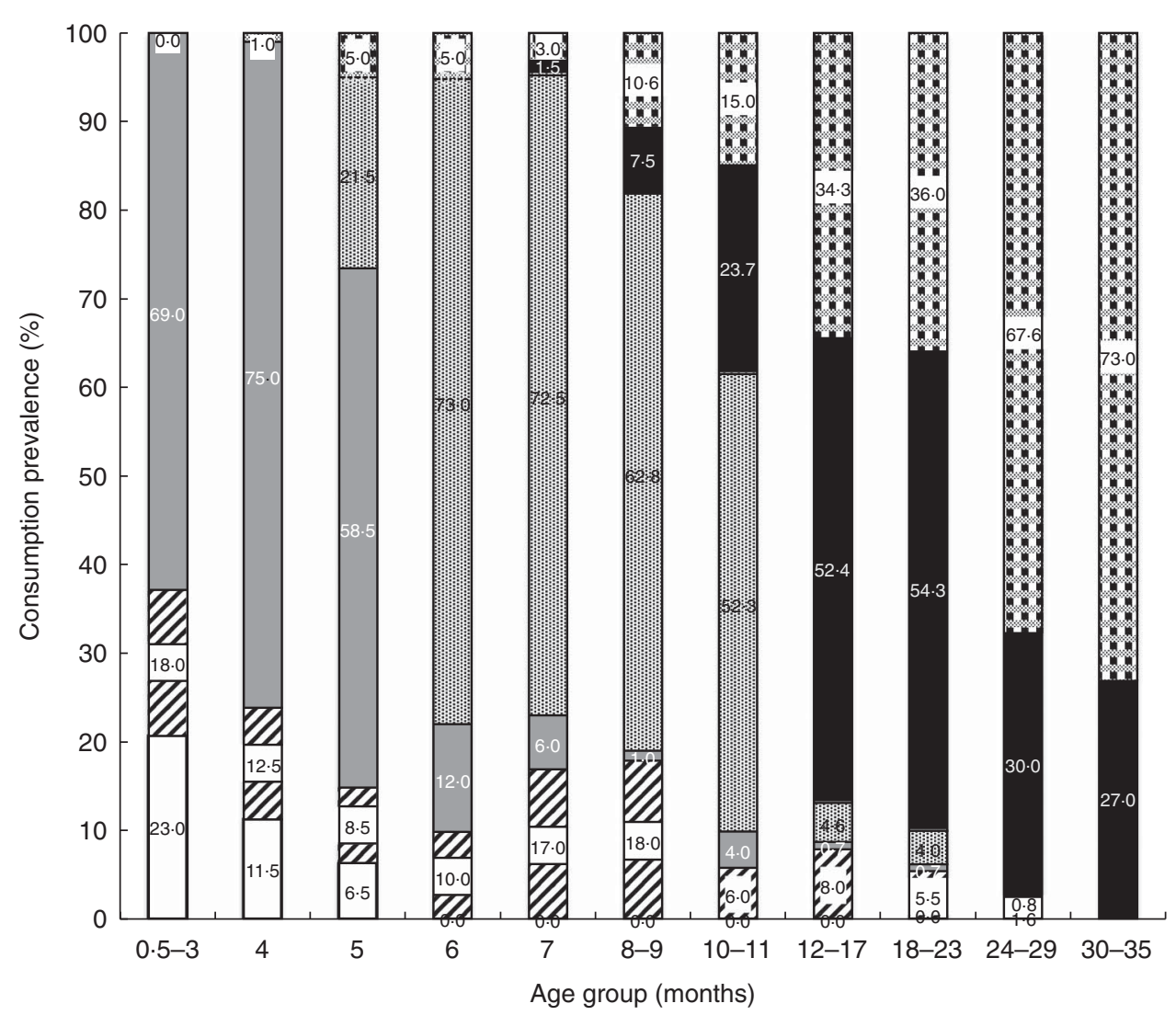

Fig. 4 Prevalence of the consumption of each category of milk ( $\square$, exclusively breast-fed; $\square$, partially breast-fed; $\square$, infant formula; 圈, follow-on formula; $\square$, growing-up milk; $⿴$, cow's milk) by age among the children $(n 1184)$ in the French national survey on food consumption of children under 3 years of age (Nutri-Bébé 2013)

\section{Feeding practices}

\section{Milk intake}

At the time of the survey (Table 2), a total of forty-two infants were exclusively breast-fed (EBF); twenty-three were younger than 4 months and none was older than 5 months. On average, they had seven feedings per day with a mean duration of $21 \mathrm{~min}$ ( $95 \%$ CI 18, 23 min) each; $21 \%$ of mothers used sometimes a breast pump. Another 107 infants were partially breast-fed (PBF), with four breast-feedings per day of 18 (95\% CI 14, 21) min mean duration each; $73 \%$ of them were previously EBF. Breastfeeding prevalence, whether exclusive or partial, was $31 \%$ before 4 months of age, $24 \%$ at 4 months of age, $10 \%$ at 5 months, $8 \%$ between 12 and 17 months, 5.5\% between 18 months and 2 years, and $1.6 \%$ after 2 years, with no more BF children after 30 months (Fig. 4).

One thousand and thirty-five children were bottle-fed (Table 2). Among them, $41 \%$ were previously EBF and $15 \%$ PBF. Breast-feeding was stopped in $29 \%$ of the EBF children before the age of 2 months, in $27 \%$ between 2 and 4 months of age and in $44 \%$ after 4 months. Mean age at this weaning was $17 \cdot 8$ (SD 17.9) weeks. Respectively 26, 25 and $49 \%$ of the PBF children were weaned at the same time (NS). The prevalence of present or past breast- feeding in the main sample (without the oversample) was $67 \%$. Mothers who breast-fed or who did it previously were more likely to belong to the PCS + group (70 v. $60 \%$ in PCS - and $46 \%$ in inactive group; $P=0.001$ ); there was no difference between primiparous and multiparous. The type of milk consumed according to age by NBF children is detailed in Fig. 4. It was mainly infant formula (IF) before the age of 6 months. IF was continued in $86 \%$ of cases beyond the age of 6 months; the mean age of abandonment of this IF was $6.1 v .4 .7$ months in 2005 $(P<0.0001)$. For $91 \%$ of infants the IF was relayed by a follow-on-formula (FOF), which was continued on average until the age of 13 months ( $v .12 .5$ months in 2005; NS). Sixty-three per cent of children subsequently received a GUM until a mean age of 31.2 months. At the time of the survey, $32 \%$ of the overall NBF children consumed GUM v. $24 \%$ in 2005 ( $P=0.0004)$. GUM was consumed by $17 \%$ between 8 and 11 months of age and $53 \%$ between 12 and 17 months. Thirty-two per cent of the nursing mothers gave GUM $v$. $25 \%$ of mothers who never breast-fed $(P=0.005)$. Mothers who used GUM did so in $66 \%$ of cases on advice from a health professional. Compared with the 2005 results, there was a tendency to introduce FOF later (6-7 v. 4-5 months). GUM was consumed more often, with a gain of $8 \%$ for all ages at the expense of the 
Table 3 Average quantities ( $\mathrm{g} / \mathrm{d}$ ) of milk, milky drinks, dairy products and cheese consumed by age by non-breast-fed children ( $n$ 1035) in the French national survey on food consumption of children under 3 years of age (Nutri-Bébé 2013)

\begin{tabular}{|c|c|c|c|c|c|c|c|c|}
\hline \multirow[b]{2}{*}{ Age group (months) } & \multicolumn{8}{|c|}{ Type } \\
\hline & IF & FOF & GUM & $\mathrm{CM}$ & MD & Dairy & Cheese & Total \\
\hline $0 \cdot 5-3$ & 833.1 & 4.4 & 0.0 & 0.0 & 0.0 & 1.4 & 0.0 & 838.9 \\
\hline 4 & 846.5 & 1.2 & 0.0 & $11 \cdot 2$ & 28.4 & 3.8 & 0.0 & 891.1 \\
\hline 5 & 584.2 & $155 \cdot 3$ & 0.0 & 36.0 & $22 \cdot 4$ & $18 \cdot 8$ & 0.0 & $816 \cdot 7$ \\
\hline 6 & 125.4 & $490 \cdot 7$ & 0.0 & $25 \cdot 1$ & 38.9 & $57 \cdot 3$ & 0.5 & 737.9 \\
\hline 7 & $50 \cdot 6$ & $484 \cdot 3$ & $9 \cdot 4$ & $20 \cdot 8$ & $49 \cdot 4$ & $91 \cdot 1$ & 0.9 & 706.5 \\
\hline $8-9$ & $8 \cdot 1$ & 382.8 & $46 \cdot 2$ & $53 \cdot 7$ & 36.5 & $113 \cdot 3$ & $2 \cdot 0$ & $642 \cdot 6$ \\
\hline $10-11$ & $27 \cdot 8$ & 277.9 & 109.1 & 55.4 & $26 \cdot 1$ & $151 \cdot 6$ & 3.9 & 651.8 \\
\hline $12-17$ & 4.2 & 23.3 & 233.3 & $164 \cdot 6$ & 23.7 & 133.5 & $8 \cdot 8$ & 591.4 \\
\hline $18-23$ & 2.5 & 20.5 & 221.9 & 152.4 & 19.1 & 132.8 & 9.8 & 559.0 \\
\hline 24-29 & 0.0 & $2 \cdot 6$ & $119 \cdot 4$ & $213 \cdot 0$ & $15 \cdot 8$ & 131.5 & $10 \cdot 0$ & $492 \cdot 3$ \\
\hline 30-35 & 0.0 & 0.0 & 68.0 & 209.8 & $16 \cdot 6$ & 121.3 & $12 \cdot 7$ & 428.4 \\
\hline
\end{tabular}

IF, infant formula; FOF, follow-on formula; GUM, growing-up milk; CM, cow's milk; MD, milky drinks.

consumption of cow's milk (CM). Between 1 and 2 years, most of the children received GUM. Five per cent of the children were already given $\mathrm{CM}$ at the age of 5 months. CM was consumed by $15 \%$ at $10-11$ months, more than $34 \%$ after 1 year and more than $65 \%$ after 2 years of age. The average age of changing to $\mathrm{CM}$ was 13.8 months in 2013 v. 12 months in 2005 ( $P=0 \cdot 0001)$. Mothers who had breast-fed their baby introduced $\mathrm{CM}$ later than the $\mathrm{NBF}$ ones (15.1 v. 12.9 months; $P=0.0003)$. Mothers who used $\mathrm{CM}$ did so in $75 \%$ of cases according to their instinct or experience; $42 \%$ of them justified their choice by a more interesting price. In $88 \%$ of cases the CM used was a semiskimmed one, as it was in 2005. Only two children between 12 and 17 months were drinking goat's milk, and two others of the same age group were drinking vegetable commercial beverage. Up to 1 year of age about half of children drunk their milk warm, $40 \%$ at room temperature and $10 \%$ drank cold milk. The mean quantities of milk and dairy products/cheese consumed are given in Table 3. On average, milk consumption (IF, FOF, GUM or CM) was about $840 \mathrm{ml} / \mathrm{d}$ before 3 months of age, reached a maximum of about $900 \mathrm{ml} / \mathrm{d}$ at 4 months, then decreased to a little bit less than $500 \mathrm{ml} / \mathrm{d}$ at $8-9$ months and to less than $350 \mathrm{ml} / \mathrm{d}$ after the age of 2 years. At the same time, the consumption of dairy products increased gradually but was insufficient to reach a total of $500 \mathrm{~g}$ of milk plus dairy products (including cheese) daily at the age of 3 years. Cheese contributed significantly (about $10 \mathrm{~g} / \mathrm{d}$ on average) to dairy products from the age of 1 year.

\section{Complementary feeding}

The mean age for the introduction of solid foods other than milk was $5 \cdot 4$ (SD 2.1) months, while it was between 4 and 5 months in $2005(P=0.032) ; 6 v .13 \%$ of children were introduced to solids before the age of 3 months; $31 v .33 \%$ at 4 months; $23 v .32 \%$ at 5 months; and $31 v$. $16 \%$ at 6 months $(P<0.0001)$. Solid foods were introduced after 7 months of age in $10 \%$ of children, $v .6 \%$ in 2005 . The mean age for consuming a full meal with solids and without milk was 9.9
(SD 5.5) months. In chronological order, the first three food types consumed, apart from milk, were fruits by $68 \%$ of the infants, vegetables by $77 \%$ and dairy products by $42 \%$. The numbers were similar in 2005. Among the first foods introduced, cereals were consumed by $31 \%$ of infants, potatoes by $20 \%$, meat or fish by $13 \%$, and rice or pasta by $7 \%$. On average vegetables were consumed for the first time at 5.6 months, fruits at 5.9 months, dairy products at 5.9 months, cereals at 5.6 months, potatoes at 6.7 months, and meat or fish at 7.3 months. The relative quantitative proportion of each food category is indicated in Table 4. Specific baby foods were mainly used between 6 and 9 months, thereafter non-specific adult foods were mainly consumed. Only $4 \%$ of the mothers gave specific baby foods exclusively, and only $0 \cdot 2 \%$ of them gave only homemade foods. The different steps of introduction of food textures are described in Fig. 5. Until 8 months of age, a fine homogenised texture was used by more $90 \%$ of infants. Soft lumps were introduced after 8 months in half of the infants and pieces after 12 months. The percentage of children who occasionally or regularly consumed the same food as their parents was $26 \%$ from 8 months of age, $81 \%$ between 1 and 2 years of age, and $95 \%$ after 2 years of age. Overall, $54 \%$ of mothers reported that their child sometimes refused certain foods, mainly vegetables (54\%) or meat/fish (29\%). The same refusal rate was observed whether the child had been breast-fed or not.

\section{Modality of meals}

Eighty-six per cent of mothers fed their child themselves and $89 \%$ prepared their child's meals. Multiparous mothers were more prone to feed their child $(P<0.0001)$ and to prepare their meals $(P<0.002)$, as multiparous mothers are more often housewives (49 v. 22\%; $P<0 \cdot 0001)$, but there was no difference between $\mathrm{BF}$ and NBF mothers. Twelve per cent of children had some of their meals at a nursery or with their child-minder; this was more likely to occur when it was the first child. After 1 year of age, more than half of the children regularly ate their 
Table 4 Contribution of the different categories of foods consumed by non-breast-fed children ( $n$ 1035) according to age, expressed as a percentage of the quantity ingested daily, in the French national survey on food consumption of children under 3 years of age (Nutri-Bébé 2013)

\begin{tabular}{|c|c|c|c|c|c|}
\hline \multirow[b]{2}{*}{ Age group (months) } & \multicolumn{5}{|c|}{ Food category (\%) } \\
\hline & IF, FOF or GUM & Baby food & $\mathrm{CM}$ & Current non-specific food & Drinking-water \\
\hline $0 \cdot 5-3$ & $97 \cdot 3$ & 0.8 & 0.0 & 0.6 & $1 \cdot 3$ \\
\hline 4 & $88 \cdot 6$ & $6 \cdot 8$ & 1.2 & $2 \cdot 3$ & 1.0 \\
\hline 5 & 74.6 & $15 \cdot 4$ & $3 \cdot 6$ & $3 \cdot 7$ & $2 \cdot 7$ \\
\hline 6 & $59 \cdot 2$ & 23.5 & $2 \cdot 4$ & $12 \cdot 0$ & $2 \cdot 9$ \\
\hline 7 & $50 \cdot 3$ & 28.9 & 1.9 & $15 \cdot 5$ & 3.4 \\
\hline $8-9$ & $39 \cdot 3$ & $29 \cdot 0$ & 4.8 & $19 \cdot 6$ & $7 \cdot 3$ \\
\hline $10-11$ & 34.6 & 24.9 & 4.6 & $30 \cdot 4$ & 5.5 \\
\hline $12-17$ & $21 \cdot 1$ & $15 \cdot 2$ & $13 \cdot 3$ & 39.5 & $10 \cdot 9$ \\
\hline $18-23$ & 19.5 & $9 \cdot 2$ & $12 \cdot 2$ & $43 \cdot 7$ & $15 \cdot 4$ \\
\hline $24-29$ & $10 \cdot 0$ & 4.3 & $17 \cdot 5$ & $49 \cdot 4$ & $18 \cdot 8$ \\
\hline $30-35$ & 5.4 & 2.9 & $16 \cdot 7$ & 54.5 & 20.5 \\
\hline
\end{tabular}

IF, infant formula; FOF, follow-on formula; GUM, growing-up milk.

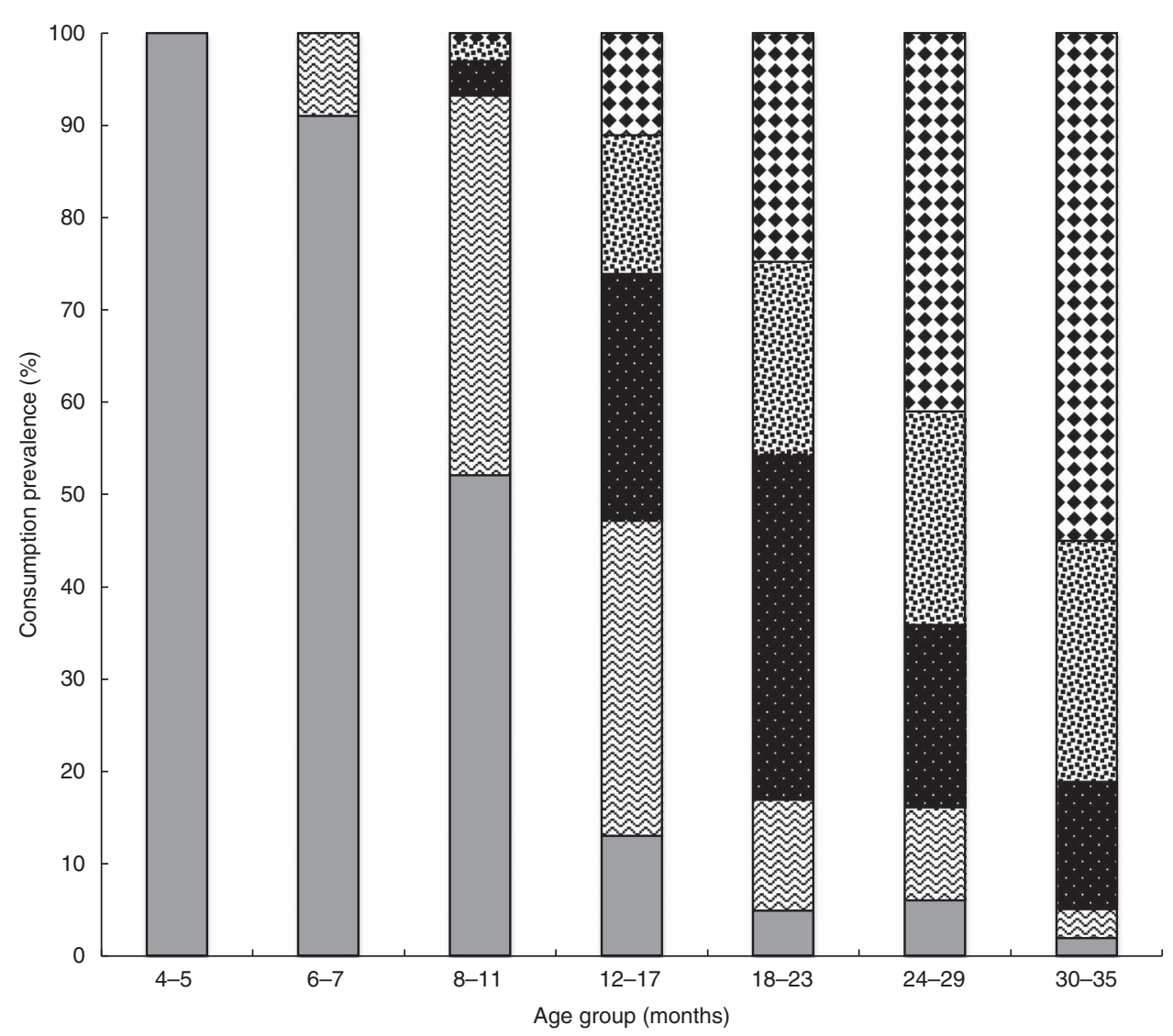

Fig. 5 Different steps of introduction of food textures ( $\square$, fine homogenised; $\otimes$, curdled; 圈, mashed with small lumps; 图, soft pieces; , pieces), represented by the percentage of children ( $n$ 894) consuming each of them according to age, once the solids have been introduced, in the French national survey on food consumption of children under 3 years of age (Nutri-Bébé 2013)

meals at the same time as their parents. Twenty-nine per cent of all children ate their meals in front of the television or any screen, which was already the case for $15 \%$ of children under 4 months. This habit was less frequent when the mother was PCS + (12\%) than with PCS - (31\%) or inactive mothers $(35 \% ; P<0 \cdot 0001)$.

\section{Physical activity}

Fifty-three per cent of the children watched a screen every day. On average, children were in front of a screen $4.3 \mathrm{~d} /$ week, with a weekly time of $195 \mathrm{~min}$. The mean screen time was 43.0 (SD 40.4 ) $\mathrm{min} / \mathrm{d}$; before the age of 1 year, the average time was approximately $30 \mathrm{~min}$ and 
reached $58 \mathrm{~min}$ after 30 months. After the age of 1 year, $40 \%$ of children moved by walking independently and $90 \%$ after 2 years. Other children were either carried or used a stroller.

\section{Discussion}

The national Nutri-Bébé 2013 study is the fifth food consumption and eating behaviour survey conducted in children under 3 years old in France by the SFAE since 1981 with an equivalent methodology ${ }^{(4-7)}$. They are the only French surveys for that age range, thus complementing the INCA surveys (Individuelle et Nationale sur les Consommations Alimentaires), which concern adults and children aged 3 years and over ${ }^{(12)}$. The analysis of data provided by these successive surveys has helped identify public health issues regarding food and nutrition, notably included in official reports aimed at defining nutrition policy ${ }^{(13,14)}$. Changing lifestyles and the evolution of commercial products require regular information updates. Other countries such as the $\mathrm{UK}^{(15)}$ and Portugal ${ }^{(16)}$ in Europe, the USA ${ }^{(17-19)}$ and Canada ${ }^{(20)}$ in North America, and fifteen different countries in Asia (Cambodia, China, India, Indonesia, Japan, Malaysia, Mongolia, Nepal, Pakistan, Philippines, Singapore, South Korea, Taiwan, Thailand, Vietnam) ${ }^{(21)}$ have taken the same approach. Their results cannot be directly compared with the French situation, given the different products available and lifestyles.

The Nutri-Bébé 2013 study has recruited a large cohort of children under 3 years of age, with a participation refusal rate of only $0.34 \%$. A total of 1184 infants and young children from $15 \mathrm{~d}$ to 3 years old were recruited, 1035 of whom were NBF. The population size was greater than that included in previous SFAE surveys, thereby helping to increase the robustness of the current study, and fully complying with the EFSA recommendations ${ }^{(8)}$. In 1981, the first survey included 649 children from 0 to 24 months of age $^{(4)}$; in 1989, 499 children from 0 to 18 months were enrolled ${ }^{(5)}$; and in 1997, 660 children from 0 to 30 months were included ${ }^{(6)}$. In 2005, 713 non-breastfed children from 1 to 35 months were recruited ${ }^{(7)}$. The inclusion number of the current survey is also notably higher than that of many other surveys that enrolled children of the same age in other countries, which have been conducted under different conditions and methods ${ }^{(15,18,19,22-24)}$. However, other surveys have enrolled a larger sample ${ }^{(17,25-27)}$

Like previous French surveys and the vast majority of other studies ${ }^{(13,16,17,20-25)}$, Nutri-Bébé 2013 is an observational cross-sectional study. To our knowledge, only one study longitudinally observed the food consumption of infants from birth to 1 year old ${ }^{(17)}$. Thanks to its robustness and recruitment based on the quota sampling method, our study can be considered a faithful representation of the mainland French population with respect to age, gender, mother's activity, PCS of the person responsible for the family, geographic distribution and size of the urban agglomeration. The perfect comparability of the populations studied in 2013 and 2005, combined with the similarity of the methodology employed, allows us to make a historical comparative analysis. Contrary to other countries, particularly the USA ${ }^{(17-19,26)}$, it is not allowed to disclose the ethnic origin of the population living in France. The quota sampling method has already been used in previous studies ${ }^{(4-7)}$ and is considered the best option in non-probabilistic sociodemographic studies of this type, as it provides the necessary statistical power ${ }^{(28)}$. A high-quality sample, with well-controlled quotas, has a negligible impact on the bias and precision of the estimates compared with simple random sampling ${ }^{(29)}$. The internal and external validity of the survey can therefore be considered satisfactory ${ }^{(30)}$. Unlike previous studies ${ }^{(4-7)}$, the eleven age groups were strictly defined, thereby increasing the accuracy of age determination for key recommendation time points such as the introduction of solids ${ }^{(31,32)}$ and different formulas (recommendations from the Directive of the European Commission on IF and FOF) ${ }^{(33)}$.

As proposed by the EFSA expert group ${ }^{(8)}$, children were weighed specifically for the survey; this was not the case in previous studies, in which the reported weight by parents was considered sufficient ${ }^{(4-7)}$. Few studies have measured children's weights and thus have been able to provide an evaluation of intake relative to actual weight $^{(15,17,24,25)}$. These studies also included the report of children's height and allowed to determine their BMI, which unfortunately could not be performed in our study. The results regarding the measured weights confirmed the normality of the study population, since $93.9 \%$ of children included had a weight-for-age between the $3 \mathrm{rd}$ and the 97th percentile of the WHO Child Growth Standards ${ }^{(10,34)}$.

In terms of both sociodemographic and nutritional results, the quality of the survey is reinforced by the fact that it combined a three non-consecutive days record and two face-to-face interviews, performed before and after data collection. The good relationship established between the interviewer and the caregiver improved compliance to the study protocol as well as the relevance of the answers ${ }^{(8)}$. The interview was computer-assisted (CAPI), as with the British surveys that occurred between 2008 and $2012^{(15)}$. The investigator could thus verify the correspondence between what was reported in the food consumption diary and the labelling of the food consumed. This practice, like the use of photographs of reference portion sizes and a measuring cup, were already used in $2005^{(7)}$. They are recommended for surveys conducted in Europe among pre-school children (4-6 years old) ${ }^{(35,36)}$ and are in line with the methods highlighted by the EFSA and the $\operatorname{IFN}^{(8,9)}$. No gold standard exists for the estimation of portion size. The EFSA expert group stressed the importance of using different ageappropriate tools and portion size aids to obtain best 
estimates for different foods. Error variability seems to be reduced when photographs and food models are used together, compared with using household measures alone ${ }^{(8)}$.

Data collection over three days provides a better estimate of daily intake compared with data collected in one single day ${ }^{(16,18,19,26)}$. The British and Canadian surveys took place over four days ${ }^{(15,27)}$. Our complete survey was conducted over a 4-month period including much of the winter and the early spring. This made it possible to avoid the difficulties associated with variations related to changes in recommendations and trends, which may occur in surveys carried out over long periods with smaller samples ${ }^{(16,18,19)}$. However, apart from the consumption of home-made fruits and vegetables, it can be sustained without factual certainty that the seasons have relatively little influence on eating habits for the age groups concerned. Nevertheless, this is just a snapshot of the study population's habits, thereby limiting the potential associations between the results obtained and a possible impact on long-term health ${ }^{(30)}$. It is of note that the majority of mothers relied primarily on instinct and personal experience, which does not prevent more than half of them from consulting a health-care professional as well, mainly the youngest mothers, the primiparas or those having a child less than 1 year old.

Breast-feeding prevalence in our survey is quite low compared with that described in other countries and even other surveys performed in France. In the ELFE Study (Etude Longitudinale Française depuis l'Enfance) based on 17562 births in 2011, 59.5\% of the newborns were EBF and $10 \cdot 2 \%$ were PBF in the maternity ward ${ }^{(37)}$. At 1 month of age, EBF and PBF prevalence were respectively 43.2 and $10.6 \%$; at 4 months, 10.0 and $33.0 \%$; and at 6 months, 9.9 and $10.0 \%$. Among 2806 infants included in the Epifane study (Épidémiologie en France de l'alimentation et de l'état nutritionnel des enfants pendant leur première année de vie) in 2012-2013, the prevalence of EBF and $\mathrm{PBF}$ at birth was 58.7 and $15.0 \%$, respectively ${ }^{(38)}$. It was respectively 21.4 and $17.8 \%$ at 3 months, 10.5 and $12.0 \%$ at 6 months, and 5.0 and $4.6 \%$ at 1 year. Median duration for exclusive or predominant breast-feeding was $24 \mathrm{~d}$. In any case, breast-feeding duration in France is far from the 6 months of EBF recommended by WHO.

For the formula-fed infants, there was in 2013 a trend to introduce FOF later than in 2005 and to consume more often GUM at the expense of the consumption of CM. Between 1 and 2 years of age most of the children were given GUM, and this was more frequent in the previously breast-fed children. Nearly one-third of the children above 1 year of age and two-thirds above 2 years of age consumed semi-skimmed milk.

Concerning complementary feeding, the feeding practices were consistent with the European and French recommendations $^{(31,32)}$, since for $54 \%$ of infants, introduction of solid foods began between 4 and 6 months, and an additional $31 \%$ began solids in the seventh month. This was different from the 2005 results when this introduction was made more readily before 6 months, and was consistent with those of the Epifane survey ${ }^{(39)}$. Younger mothers were more prone to introduce solid foods before 4 months or after 8 months. Of more concern is the number of children who, as young as 8 months old, consumed the same food as their parents and the number of children who had meals in front of a screen.

\section{Conclusion}

The Nutri-Bébé SFAE 2013 survey adds to the series of studies conducted since 1981 on the food consumption of infants and young children living in France. Compared with previous studies, its statistical power, robustness and reliability have all improved, while maintaining a very good sociodemographic representation of children under 3 years of age living in mainland France. These qualities should make it possible to obtain an accurate analysis of the eating habits and nutritional intake in that population. Even if somewhat modified in its methodology, the data collection will allow us to assess time trends in feeding and eating practices especially by comparison with the 2005 survey. This survey highlights the low rate of breastfeeding in France but shows an improvement in the observance of the recommendations concerning the use of IF, FOF and GUM. Some progress still needs to be made, particularly concerning the excessive use of semiskimmed milk. With regard to the introduction of complementary foods, the current recommendations are rather correctly followed. We may be challenged by the frequency of consumption of meals intended for adults and the importance of screen time in these very young children. Once established, the data will be essential for the medical and scientific community, the French and European authorities, and manufacturers specialised in nutrition for young children. These data will allow improved identification of nutritional deficits and excesses, in parallel to the analysis of behaviours and practices of parents regarding the nutritional intake of their children. Finally, the Nutri-Bébé 2013 study will provide a database to update children's level of exposure to pesticides, additives and contaminants according to the ANSES methodology ${ }^{(40)}$, which has already been done on the 2005 data $^{(41)}$.

\section{Acknowledgements}

Acknowledgements: The authors thank the families participating in the survey, who gave up their time to be interviewed, and who welcomed interviewers and nurses into their homes. They would also like to acknowledge the professionalism and commitment of interviewers who worked on the survey and were so important to the survey's success. The authors wish to thank everyone who contributed to the survey, especially in its design 
and supervision. Financial support: The survey was fully funded by the SFAE (Secteur Français des Aliments de l'Enfance, 9 boulevard Malesherbes, Paris 75008, France). Conflict of interest: Y.E. is employed by TNS Sofres, and G.T., A.F. and P.H. are employed by the CREDOC. Both companies received funding from the SFAE to carry out the present study. J.-P.C. contributed as a scientific consultant and received an honorarium from the CREDOC for his participation in the survey management and the result interpretation. M.B. is employed by the SFAE. R.H. and D.T. declare that they have no competing interest. Authorship: J.-P.C. was involved in the study design, data collection, analysis and interpretation of data, as well as writing of the paper. G.T. conceived the study, participated in its design and coordination, collected the data, performed the statistical analysis and helped draft the manuscript. Y.E. and A.F. collected the data and contributed to their analysis. P.H. was involved in the study design. M.B. designed, coordinated and supervised the survey and helped draft the manuscript. R.H. participated in the design of the study and helped draft the manuscript. D.T. reviewed, edited and provided comments on drafts of the manuscript. All authors saw and approved the final version. Ethics of human subject participation: This study was conducted according to the guidelines laid down in the Declaration of Helsinki. The study was conducted by TNS Sofres, an official polling institute which fulfils the following standards and industry requirements: ESOMAR professional code of conduct and standards; ISO 20252:2012 international standard for market, opinion and social research; and the French data protection act (Loi 'Informatique et Libertés'). TNS Sofres ensured to conduct the survey in accordance with the regulation on personal data protection and that respondents' personal identity is withheld. Moreover, TNS Sofres appointed a data protection officer, the 'Correspondant Informatique et Libertés', who was the point of contact between the French data protection authority (Commission Nationale de l'Informatique et des Libertés (CNIL)) and the company. The company was thus exempted of the notification process to the CNIL as far as the data processing is concerned, which is the data protection officer's responsibility. Given the type of survey conducted, namely a survey of consumption, and the characteristics developed above, the study did not require any opinion of the ethics committee. Verbal informed consent of parents was witnessed and formally recorded.

\section{Supplementary material}

To view supplementary material for this article, please visit https://doi.org/10.1017/S1368980017002518

\section{References}

1. Barker DJ (2004) Developmental origins of adult health and disease. J Epidemiol Community Health 58, 114-115.
2. Field CJ (2009) Early risk determinants and later health outcomes: implications for research prioritization and the food supply. Am J Clin Nutr 89, issue 5, 1533S-1539S.

3. Simeoni U, Bocquet A, Briend A et al.; Comité de nutrition de la Société française de pédiatrie (2016) Early origins of adult disease. Arch Pediatr 23, 443-446.

4. Boggio V, Lestradet H, Astier-Dumas M et al. (1984) Characteristics of the dietary intake of French children from 3 to 24 months of age. Arch Fr Pediatr 41, 499-505.

5. Boggio V \& Fantino M (1991) Évolution récente des apports nutritionnels chez les nourrissons français: comparaison de 2 enquêtes nationales réalisées en 1981 et 1989. In Journées parisiennes de pédiatrie, pp. 275-282. Paris: Médecine-Sciences Flammarion.

6. Boggio V, Grossiord A, Guyon S et al. (1999) Food consumption of infants and young children in France in 1997. Arch Pediatr 6, 740-747.

7. Fantino M \& Gourmet E (2008) Energy consumption and nutritional intake in non breast-fed children under 36 months old. Arch Pediatr 15, 446-455.

8. European Food Safety Authority (2009) General principles for the collection of national food consumption data in the view of a pan-European dietary survey. EFSA J 7, 1435.

9. Institut Français de Nutrition (1996) Abords méthodologiques des enquêtes de consommation alimentaire chez l'homme. Dossier scientifique $\mathrm{n}^{\circ}$ 8. http://alimentationsante.org/wp-content/uploads/2011/07/dossier-scient-8.pdf (accessed September 2017).

10. World Health Organization (2006) Anthro 2005, Beta Version Feb 17th, 2006: Software for Assessing Growth and Development of the World's Children. Geneva: WHO; available at http://www.who.int/childgrowth/software/en/

11. Centre d'Information sur la Qualité des Aliments (2012) Agence nationale de sécurité sanitaire de l'alimentation, de l'environnement et du travail. French food composition table, Table CIQUAL 2012. http://www.afssa.fr/TableCIQUAL/ (accessed March 2013).

12. Lioret S, Dubuisson C, Dufour A et al. (2010) Trends in food intake in French children from 1999 to 2007: results of the INCA (étude Individuelle Nationale de Consommations Alimentaires) dietary surveys. Br J Nutr 103, 585-601.

13. Haut comité de la santé publique (year?) Pourx une politique nutritionnelle de santé publique en France, enjeux et propositions. http://www.sante.gouv.fr/le-rapport-du-hautcomite-de-la-sante-publique-pour-une-politique-nutritionnellede-sante-publique-en-france-juin-2000.html (accessed April 2014).

14. Hercberg S (2014) Development of a nutritional policy designed to meet public health challenges. Sante Publique 26, 281-282.

15. Bates B, Lennox A, Prentice A et al. (2014) National Diet and Nutrition Survey Results from Years 1, 2, 3 and 4 (combined) of the Rolling Programme (2008/2009-2011/12). https://www.gov.uk/government/uploads/system/uploads/ attachment_data/file/594361/NDNS_Y1_to_4_UK_report_full_ text_revised_February_2017.pdf (accessed September 2017).

16. Marques-Vidal P, Ravasco P, Dias CM et al. (2006) Trends of food intake in Portugal, 1987-1999: results from the National Health Surveys. Eur J Clin Nutr 60, 1414-1422.

17. Fein SB, Labiner-Wolfe J, Shealy KR et al. (2008) Infant Feeding Practices Study II: study methods. Pediatrics 122, Suppl. 2, S28-S35.

18. Curtin LR, Mohadjer LK, Dohrmann SM et al. (2012) The National Health and Nutrition Examination Survey: sample design, 1999-2006. Vital Health Stat 2 issue 155, 1-39.

19. Johnson CL, Dohrmann SM, Burt VL et al. (2014) National Health and Nutrition Examination Survey: sample design, 2011-2014. Vital Health Stat 2 issue 166, 1-33.

20. Office of Nutrition Policy and Promotion, Health Products and Food Branch, Health Canada (2006) Canadian 
Community Health Survey Cycle 2.2, Nutrition (2004). A Guide to Accessing and Interpreting the Data. https://www. canada.ca/content/dam/hc-sc/migration/hc-sc/fn-an/alt_ formats/hpfb-dgpsa/pdf/surveill/cchs-guide-escc-eng.pdf (accessed April 2014).

21. Song S \& Song WO (2014) National nutrition surveys in Asian countries: surveillance and monitoring efforts to improve global health. Asia Pac J Clin Nutr 23, 514-523.

22. Kudlova E \& Rames J (2007) Food consumption and feeding patterns of Czech infants and toddlers living in Prague. EurJ Clin Nutr 61, 239-247.

23. Tsuboyama-Kasaoka N, Takizawa A, Tsubota-Utsugi M et al. (2013) Dietary intake of nutrients with adequate intake values in the dietary reference intakes for Japanese. $J$ Nutr Sci Vitaminol (Tokyo) 59, 584-595.

24. Zhou SJ, Gibson RA, Gibson RS et al. (2012) Nutrient intakes and status of preschool children in Adelaide, South Australia. Med J Aust 196, 696-700.

25. Coimbra CE Jr, Ventura Santos R, Welch et al. (2013) The First National Survey of Indigenous People's Health and Nutrition in Brazil: rationale, methodology, and overview of results. BMC Public Health 13, 52.

26. Butte NF, Fox MK, Briefel RR et al. (2010) Nutrient intakes of US infants, toddlers, and preschoolers meet or exceed dietary reference intakes. J Am Diet Assoc 110, 12 Suppl., S27-S37.

27. Friel JK, Hanning RM, Isaak CA et al. (2010) Canadian infants' nutrient intakes from complementary foods during the first year of life. BMC Pediatrics 10, 43.

28. Bornstein MH, Jager J \& Putnick DL (2013) Sampling in developmental science: situations, shortcomings, solutions, and standards. Dev Rev 33, 357-370.

29. Raab G (2009) Technical Annex to Davidson S, Martin C, Treanor S. Scottish Environmental Attitudes and Behaviours Survey 2008: Technical Report. http://www.scotland.gov.uk/ Resource/Doc/265441/0079493.pdf (accessed June 2014).

30. Bruemmer B1, Harris J, Gleason P et al. (2009) Publishing nutrition research: a review of epidemiologic methods. J Am Diet Assoc 109, 1728-1737.

31. European Food Safety Authority, Panel on Dietetic Products, Nutrition and Allergies (2009) Scientific Opinion on the appropriate age for introduction of complementary feeding of infants. EFSA J 7, 1423.

32. Turck D, Dupont C, Vidailhet M et al.; Comité de nutrition de la Société française de pédiatrie (2015) Complementary feeding: evolving concepts and recommendations. Arch Pediatr 22, 457-460.
33. Commission of the European Communities (2006) Commission Directive 2006/141/EC of 22 December 2006 on infant formulae and follow-on formulae and amending Directive 1999/21/EC. http://eur-lex.europa.eu/legal-content/ EN/TXT/PDF/?uri=CELEX:32006L0141\&from=EN (accessed October 2013).

34. de Onis M, Garza C, Onyango AW et al.; Comité de nutrition de la Société française de pédiatrie (2009) WHO growth standards for infants and young children. Arch Pediatr 16, $47-53$.

35. Andersen LF, Lioret S, Brants $\mathrm{H}$ et al; EFCOVAL Consortium (2011) Recommendations for a trans-European dietary assessment method in children between 4 and 14 years. Eur J Clin Nutr 65, Suppl. 1, S58-S64.

36. Nelson M, Atkinson M \& Darbyshire S (1994) Food photography. I: The perception of food portion size from photographs. Br J Nutr 72, 649-663.

37. Wagner S, Kersuzan C, Gojard S et al. (2015) Durée de l'allaitement en France selon les caractéristiques des parents et de la naissance. Résultats de l'étude longitudinale Française Elfe, 2011. Bull Epidémiol Hebd 29, 522-532, available at http://www.invs.sante.fr/beh/2015/29/2015_29_1.html

38. Salanave B, De Launay C, Boudet-Berquier J et al. (2014) Durée de l'allaitement maternel en France (Épifane 20122013). Bull Epidémiol Hebd 27, 450-457, available at http:// www.invs.sante.fr/beh/2014/27/2014_27_2.html

39. Boudet-Berquier J, Salanave B, de Launay C et al. (2016) Introduction of complementary foods with respect to French guidelines: description and associated socioeconomic factors in a nationwide birth cohort (Epifane survey). Matern Child Nutr 13, issue 3, doi: 10.1111/ mon.12339

40. Agence nationale de sécurité sanitaire de l'alimentation, de l'environnement et du travail (2013) Note d'appui scientifique et technique de l'Agence nationale de sécurité sanitaire de l'alimentation, de l'environnement et du travail relatif à "l'Etude de l'alimentation totale française ». https:// www.anses.fr/fr/system/files/PASER2006sa0361-An01.pdf (accessed June 2017).

41. Agence nationale de sécurité sanitaire de l'alimentation, de l'environnement et du travail (2016) Avis de l'Agence nationale de sécurité sanitaire de l'alimentation, de l'environnement et du travail l'environnement et du travail relatif à l'exposition alimentaire des enfants de moins 3 ans à certaines substances. https://www.anses.fr/fr/system/files/ ERCA2010SA0317Ra.pdf (accessed June 2017). 